\title{
DOS NUEVAS ESPECIES DE HECHTIA (BROMELIACEAE; PITCAIRNIOIDEAE) DEL CENTRO DE MÉXICO
}

\author{
Adolfo Espejo-Serna ${ }^{1}$, Ana Rosa López-Ferrari ${ }^{1}$ e Ivón Ramírez-Morillo ${ }^{2}$ \\ ${ }^{1}$ Universidad Autónoma Metropolitana - Iztapalapa, División de Ciencias \\ Biológicas y de la Salud, Departamento de Biología, Herbario Metropolitano, \\ Apdo. postal 55-535, 09340 México, D.F., México. aes@xanum.unam.mx \\ ${ }^{2}$ Centro de Investigación Científica de Yucatán, A.C. Herbario CICY. Calle 43 \\ Núm. 130, Colonia Chuburná de Hidalgo, 97200 Mérida, Yucatán, México. \\ ramirez@cicy.mx
}

\section{RESUMEN}

Se describen e ilustran dos nuevas especies de Hechtia, H. pretiosa y H. zamudioi. Ambos taxa son endémicos del centro de México, el primero de Guanajuato y el segundo de Querétaro.

Palabras clave: Bromeliaceae, Guanajuato, Hechtia, México, Querétaro.

\section{ABSTRACT}

Two new species of Hechtia, H. pretiosa and H. zamudioi are described and illustrated. Both taxa are endemic of central Mexico, the former is known from Guanajuato and the second from Querétaro.

Key words: Bromeliaceae, Guanajuato, Hechtia, Mexico, Querétaro.

El género Hechtia es prácticamente mexicano, ya que 94.3\% de sus 53 taxa conocidos (Espejo et al., 2004, 2007; Luther, 2006) se concentra dentro de los límites del territorio nacional. Sin embargo, estamos lejos de tener completo el inventario definitivo del género, ya que existen todavía varios taxa por describir.

Hechtia fue, hasta hace poco, uno de los géneros menos atendidos por los botánicos mexicanos, dadas las características de sus representantes: plantas dioicas, por lo general robustas y bastante agresivas, con hojas espinosas y con períodos de 
floración muy cortos, lo que aunado a su distribución principalmente erémica, impidió tener colecciones completas y representativas de las especies que lo forman. El aumento, en las últimas décadas, de la exploración botánica en el país ha permitido contar con ejemplares más completos y de mejor calidad, lo que seguramente se reflejará en un mayor entendimiento del género.

En el curso de la elaboración del fascículo de las Bromeliaceae para la Flora del Bajío y de Regiones Adyacentes detectamos varias poblaciones del género Hechtia que corresponden, sin duda, a especies no descritas, para las cuales proponemos los siguientes nombres:

Hechtia pretiosa Espejo \& López-Ferrari, sp. nov. Figs. 1 y 3A

Herbae rosulatae, stoloniferae, florens usque ad $1.65 \mathrm{~m}$ altae; caules breves, inconspicui, stolones cylindrici, graciles, $40-50 \mathrm{~cm}$ longi, 3-4 mm diametro, bracteati; folia permulta, carnosa, laminae virides-citrinae triangulares, $30-50 \mathrm{~cm}$ longae, 2.2-3.5 cm latae, supra glabrae, subtus albo-lepidotae, margines spinas gerentes; spinae recurvatae, $2.5-5 \mathrm{~mm}$ longae, axillis albo-lepidotis. Inflorescentiae laterales, erectae, simplices vel bipartitae; rami masculini cylindrici, $5-46 \mathrm{~cm}$ longi, $2-2.5 \mathrm{~cm}$ diametro; flores masculini rosei vel magentei, petala et sepala ad basim per 5.5-7 $\mathrm{mm}$ connata, limbus petalorum ellipticus, $6-8 \mathrm{~mm}$ longus, 3.5-4 mm latus, filamenta laminaria, triangularia vel longe triangularia, $2-5 \mathrm{~mm}$ longa, antherae flavae, ellipticae vel oblongae, 1-1.5 mm longae; rami feminei cylindrici, $8-45 \mathrm{~cm}$ longi, 2.1-2.5 $\mathrm{cm}$ diametro, flores feminei rosei vel magentei, petala elliptica, 8-9 mm longa, 3-5 $\mathrm{mm}$ lata; staminodia alba, triangularia, 2-3 $\mathrm{mm}$ longa, antheris absentibus, ovarium ovoideum, roseum, 6-10 mm longum, 3-4 mm diametro. Rami in fructu oblongi, capsula ovoidea, pallide brunnea, $0.9-1.3 \mathrm{~cm}$ longa, $8-9 \mathrm{~mm}$ diametro, nitida.

Hierbas rupícolas, arrosetadas, estoloníferas, formando nuevas rosetas en el ápice de los delgados estolones, en flor de hasta $1.65 \mathrm{~m}$ de alto, las rosetas compactas, cespitosas, de hasta $25 \mathrm{~cm}$ de alto y $40 \mathrm{~cm}$ de diámetro, formando grupos pequeños; los estolones cilíndricos, alargados, delgados, de 40 a $50 \mathrm{~cm}$ de largo, de 3 a $4 \mathrm{~mm}$ de diámetro, bracteados, las brácteas ovado-triangulares, de 3 a $3.5 \mathrm{~cm}$ de largo, de 1 a $1.2 \mathrm{~cm}$ de ancho, largamente acuminadas, espinosas en los márgenes, pungentes en el ápice, imbricadas, densamente lepidotas en el envés; tallos cortos, inconspicuos. Hojas numerosas, carnosas, las vainas amarillas pálidas a pardas claras, anchamente ovadas a subcuadradas, de 4 a $5.5 \mathrm{~cm}$ de largo, de ca. $5 \mathrm{~cm}$ de ancho, lustrosas, glabras, las láminas de color verde primavera (exotica horticulture color 


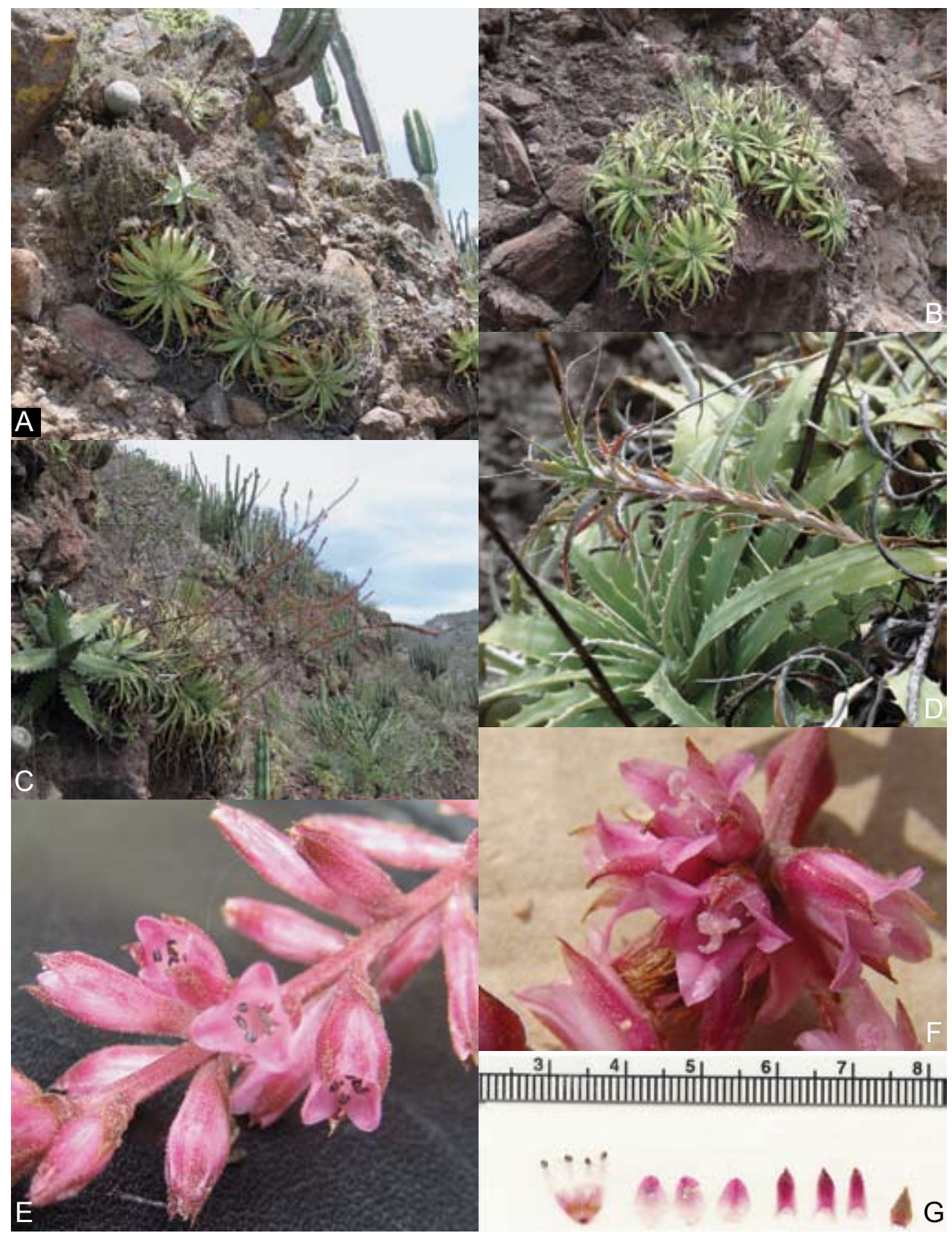

Fig. 1. Hechtia pretiosa. A. y B. hábito; C. plantas en antesis; D. estolón; E. flores masculinas; F. flores femeninas; G. flor masculina disecada. Fotografías de A. Espejo. 
guide, Graf, 1980), largamente triangulares, de 30 a $50 \mathrm{~cm}$ de largo, de 2.2 a $3.5 \mathrm{~cm}$ de ancho, glabras en la haz, densamente blanco-lepidotas en el envés, de apariencia pardo-dorado-lepidota cuando secas, atenuadas y largamente acuminadas y pungentes en el ápice, espinosas en los márgenes, recurvadas formando una roseta globosa a semiglobosa; las espinas curvadas y ascendentes, verdes a pardas, de 2.5 a $5 \mathrm{~mm}$ de largo, separadas entre sí de 7 a $12 \mathrm{~mm}$, con escamas blancas en las axilas. Inflorescencias laterales, surgiendo entre las hojas y a los lados de la roseta, erectas, procumbentes, racemosas a paniculadas; inflorescencias masculinas de 90 a $165 \mathrm{~cm}$ de alto, con 4 a 9 ramas laterales, el escapo rojizo a pardo-rojizo, cilíndrico, algo aplanado en la base, de 50 a $86 \mathrm{~cm}$ de largo, de 2 a $11 \mathrm{~mm}$ de diámetro; brácteas del escapo pardas claras, triangulares a triangular-lanceoladas, de 1.4 a $4.5 \mathrm{~cm}$ de largo, de 4.5 a $13 \mathrm{~mm}$ de ancho, acuminadas a largamente acuminadas, las basales densamente imbricadas y mucho más largas que los entrenudos, las apicales mucho más cortas que los entrenudos, enteras a ligeramente erosas en los márgenes, densamente lepidotas en el envés, glabrescentes en la haz; las ramas divaricadas a ascendentes, una por nudo, cilíndricas, de 5 a $22 \mathrm{~cm}$ de largo, la terminal de 25 a $46 \mathrm{~cm}$ de largo, de 2 a $2.5 \mathrm{~cm}$ de diámetro; brácteas primarias pardas claras, ovadas a ovado-triangulares, de 1.8 a $2.3 \mathrm{~cm}$ de largo, de 6 a $8 \mathrm{~mm}$ de ancho, con tricomas capitados glandulares esparcidamente dispuestos en el envés, lo que les da una apariencia papilosa, erosas, conspicuamente nervadas, acuminadas; brácteas florales rosadas a pardo-rosadas, ovadas a ovado-triangulares, acuminadas, de 6 a $8 \mathrm{~mm}$ de largo, de 3 a $4.5 \mathrm{~mm}$ de ancho, levemente erosas, con tricomas capitados glandulares, lo que les da una apariencia papilosa, conspicuamente nervadas; flores polísticas, divaricadas a reclinadas, laxamente dispuestas, numerosas por rama, actinomorfas, tubiformes, sésiles a subsésiles; sépalos rosados a pardo-rosados, oblongos a lanceolado-oblongos, el limbo de 6 a $8.5 \mathrm{~mm}$ de largo, de 2.5 a $3.5 \mathrm{~mm}$ de ancho, agudos y cortamente apiculados en el ápice, con tricomas capitados glandulares, lo que les da una apariencia papilosa, conspicuamente nervados, connados en la base entre sí y con los pétalos formando un tubo perigonial de 5.5 a $7 \mathrm{~mm}$ de largo; pétalos rosados, elípticos, el limbo de 6 a $8 \mathrm{~mm}$ de largo, de 3.5 a $4 \mathrm{~mm}$ de ancho, redondeados en el ápice, con tricomas capitados glandulares muy esparcidamente dispuestos, lo que les da una apariencia papilosa; estambres desiguales, tres cortos y tres largos, fusionados en la base con el tubo perigonial, los filamentos blancos, laminares, triangulares a largamente triangulares, de 2 a $5 \mathrm{~mm}$ de largo, las anteras de color púrpura oscuro, dorsifijas, elípticas a oblongas, de 1 a $1.5 \mathrm{~mm}$ de largo; ovario vestigial, en la parte basal de tubo perigonial; inflorescencias femeninas de 70 a $160 \mathrm{~cm}$ de alto, simples o con hasta 7 ramas laterales, el escapo cilíndrico, algo aplanado en la base, de 45 
a $105 \mathrm{~cm}$ de largo, de 4 a $10 \mathrm{~mm}$ de diámetro, rojizo a pardo-rojizo, glabro; brácteas del escapo pardas claras, triangulares a triangular lanceoladas, de $2.5 \mathrm{a} 4 \mathrm{~cm}$ de largo, de 9 a $13 \mathrm{~mm}$ de ancho, lepidotas sobre todo en la parte central y apical, glabrescentes, enteras, acuminadas a largamente acuminadas, iguales en longitud o ligeramente más largas que los entrenudos, disminuyendo gradualmente de tamaño hacia el ápice, las ramas divaricadas, una por nudo, cilíndricas, de 8 a $19 \mathrm{~cm}$ de largo, la terminal de 15 a $45 \mathrm{~cm}$ de largo, de 2.1 a $2.5 \mathrm{~cm}$ de diámetro; brácteas primarias pardas claras, triangulares a ovado-triangulares, de 2 a $2.5 \mathrm{~cm}$ de largo, de 7 a $8 \mathrm{~mm}$ de ancho, enteras, esparcidamente papilosas, conspicuamente nervadas, largamente acuminadas; brácteas florales rosadas a pardo-rosadas, triangulares a ovado-triangulares, de 8 a $13 \mathrm{~mm}$ de largo, de 4 a $4.5 \mathrm{~mm}$ de ancho, leve e irregularmente erosas, con tricomas capitados glandulares, lo que les da una apariencia papilosa, conspicuamente nervadas, acuminadas; flores polísticas, laxamente dispuestas, numerosas por rama, actinomorfas, tubiformes, sésiles a subsésiles; sépalos rosados a pardorosados, largamente triangulares, agudos y cortamente apiculados, de 7 a $11 \mathrm{~mm}$ de largo, de 4 a $5 \mathrm{~mm}$ de ancho, conspicuamente nervados, carinados hacia la base, levemente erosos, con tricomas capitados glandulares, lo que les da una apariencia papilosa; pétalos rosados, elípticos, de 8 a $9 \mathrm{~mm}$ de largo, de 3 a $5 \mathrm{~mm}$ de ancho, redondeados y muy cortamente apiculados en el ápice, con tricomas capitados glandulares esparcidamente dispuestos, lo que les da una apariencia papilosa, sobre todo hacia el centro y el ápice; ovario verde, ovoide a largamente ovoide, de 6 a $10 \mathrm{~mm}$ de largo, de 3 a $4 \mathrm{~mm}$ de diámetro, con tricomas capitados glandulares, lo que le da una apariencia papilosa y con tricomas pedados esparcidamente dispuestos, cubierto en la base por el tubo perigonial, el cual forma un pseudohipantio, estigmas tres, blancos en la base, rosados en el ápice, filiformes, recurvados hacia el ápice, de ca. 4 $\mathrm{mm}$ de largo, papilosos en la parte interna; estaminodios 6 , laminares, triangulares, de 2 a $3 \mathrm{~mm}$ de largo, blancos, sin anteras. Cápsula de color verde seco, rojiza hacia el ápice, parda clara cuando seca, lustrosa, esparcidamente escamosa, ovoide, de 9 a $13 \mathrm{~mm}$ de largo, de 8 a $9 \mathrm{~mm}$ de diámetro, los pedicelos acrescentes y recurvados; semillas pardas claras, fusiformes, rectas a falcadas, de 5 a $6 \mathrm{~mm}$ de largo por ca. 0.5 mm de diámetro, con una carina longitudinal y caudadas en el ápice.

Tipo: México, Guanajuato, municipio de Xichú, ca. $6.5 \mathrm{~km}$ después de El

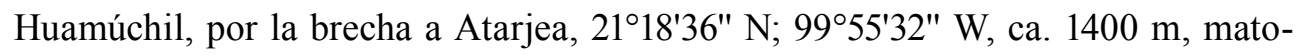
rral con cactáceas columnares (Myrtillocactus, Stenocereus) sobre sustratos rocosos ígneos, 13.IV.2007, planta masculina, A. R. López-Ferrari, A. Espejo, J. Ceja, A. Mendoza R. y S. Zamudio R. 3268 (holotipo: UAMIZ; isotipo: IEB). 
Paratipos: México, Guanajuato, municipio de Xichú, ca. $6.5 \mathrm{~km}$ después de El Huamúchil, por la brecha a Atarjea, $21^{\circ} 18^{\prime} 36^{\prime \prime} \mathrm{N}, 99^{\circ} 55^{\prime} 32^{\prime \prime} \mathrm{W}$, ca. $1400 \mathrm{~m}$, matorral con cactáceas columnares (Myrtillocactus, Stenocereus) sobre sustratos rocosos ígneos, 13.IV.2007, planta femenina, A. R. López-Ferrari, A. Espejo, J. Ceja, A. Mendoza R. y $S$. Zamudio R. 3267 (IEB, UAMIZ), $6.5 \mathrm{~km}$ al NE de El Huamúchil, por la brecha a Atarjea, $21^{\circ} 18^{\prime} \mathrm{N}, 9^{\circ} 55^{\prime} 47^{\prime \prime} \mathrm{W}, 1400 \mathrm{~m}$, matorral crasicaule con Stenocereus dumortieri, Stenocereus queretaroensis y Myrtillocactus, sobre peñas de rocas ígneas, 12.IX.1997, planta masculina, S. Zamudio, E. Pérez y L. Hernández 10464 (IEB, UAMIZ), $6.5 \mathrm{~km}$ al NE de El Huamúchil, por la brecha a Atarjea, 21 ${ }^{\circ} 18^{\prime} 36^{\prime \prime}$ N, 99 $55^{\prime} 32^{\prime \prime} \mathrm{W}, 1350 \mathrm{~m}$, laderas de rocas ígneas con Myrtillocactus geometrizans, Stenocereus queretaroensis y Stenocereus dumortieri, 13.IV.2007, planta masculina, S. Zamudio y cols. 13701 (IEB), planta femenina, S. Zamudio y cols. 13702 (IEB), entre Xichú y El Guamúchil, en riscos arriba de la carretera, $3 \mathrm{~km}$ abajo del puerto, 18.III.1995, prensado 2.V.1996, planta femenina, E. Aguilar Mendoza y Ch. Glass 16 (IEB, UAMIZ).

Distribución y hábitat: Hechtia pretiosa se conoce únicamente del municipio de Xichú (Fig. 4), en donde crece en riscos y taludes de rocas ígneas, formando colonias más bien pequeñas. Dicho municipio, ubicado en el noreste del estado de Guanajuato, fue durante largo tiempo desconocido desde el punto de vista botánico, debido principalmente a la dificultad de acceso a la zona. Aunque diversos botánicos realizaron recolecciones aisladas entre los años 1945 y 1970, no fue sino hasta el inicio del proyecto Flora del Bajío y de Regiones Adyacentes en 1985, que se llevaron a cabo exploraciones botánicas regulares en la región, encontrándose numerosos registros nuevos (Rzedowski et. al., 1996), así como especies no descritas para la ciencia (Hernández y Zamudio, 2003), a las cuales se suma la aquí propuesta.

Etimología: El epíteto específico hace referencia al atractivo aspecto de las plantas, las cuales presentan rosetas pequeñas, estoloníferas, con hojas de color verde primavera y flores rosadas o de color magenta, relativamente grandes para el género.

Hechtia pretiosa presenta características singulares entre las que podemos mencionar la presencia de estolones largos y delgados, las escamas pedadas, el tubo floral en las flores masculinas y las flores rosadas o de color magenta, poco comunes en el género. Por lo mismo, es difícil relacionarla con cualquiera de las especies conocidas. 
El otro nuevo taxon que aquí presentamos proviene de la región septentrional del estado de Querétaro. Se trata de una especie rupícola asociada a sustratos calizos para la cual proponemos el nombre de:

Hechtia zamudioi Espejo, López-Ferrari \& I. Ramírez, sp. nov. Figs. 2 y 3B

Herbae rosulatae, florens usque ad $2 \mathrm{~m}$ altae; caulis inconspicua; folia permulta, carnosa, laminae venetae, 30-48 cm longae, albo-lepidotae, margines spinas gerentes; spinae recurvatae, $1.5-2 \mathrm{~mm}$ longae, axillis albo-lepidotis. Inflorescentiae terminales, erectae, bipartitae vel tripartitae; rami masculini oblongo-cylindrici, 15$25 \mathrm{~cm}$ longi, 2-2.3 cm diametro, flores masculini virides, petala elliptica, $6-8 \mathrm{~mm}$ longa, 3.5-4 $\mathrm{mm}$ lata, filamenta linearia, 6-7 $\mathrm{mm}$ longa, antherae flavae, oblongae, ca. $3 \mathrm{~mm}$ longae; rami feminei cylindrici, $6-10 \mathrm{~cm}$ longi, 1.7-2.3 cm diametro, flores feminei virides, petala triangularia vel ovata, $5-8 \mathrm{~mm}$ longa, $2.5-3 \mathrm{~mm}$ lata; staminodia alba, triangularia vel filiformia, $2.5-3 \mathrm{~mm}$ longa, antherae vestigiales, inconspicuae; ovarium ovoideum vel ellipsoideum, viride, 5-7 mm longum, 3-4 mm diametro. Rami in fructu cylindrici, capsula ovoidea vel globoso-ovoidea, pallide brunnea, nitida.

Hierbas rupícolas, arrosetadas, cespitosas, en flor de hasta $2 \mathrm{~m}$ de alto, las rosetas compactas, de hasta $60 \mathrm{~cm}$ de alto y de 60 a $70 \mathrm{~cm}$ de diámetro, formando extensas colonias; tallos inconspicuos. Hojas numerosas, carnosas, las vainas de color amarillo paja, anchamente ovadas a subcuadradas, de 8.5 a $9 \mathrm{~cm}$ de largo, de 8.8 a $10.2 \mathrm{~cm}$ de ancho, lustrosas, glabras en ambas superficies, produciendo un exudado amarillo, las láminas de color verde-azulado, ligeramente discoloras, largamente triangulares, de 30 a $48 \mathrm{~cm}$ de largo, de 3.5 a $5 \mathrm{~cm}$ de ancho, densamente blancolepidotas en ambas superficies, espinosas en los márgenes, acuminadas y pungentes en el ápice, rectas, formando una roseta extendida de tipo estrella; las espinas curvadas y pardas claras a rojizas en el ápice, de 1.5 a $2 \mathrm{~mm}$ de largo, separadas entre sí 6 a $15 \mathrm{~mm}$, con escamas blancas en las axilas. Inflorescencias terminales, surgiendo en el ápice o parte central de la roseta, erectas, compuestas, paniculadas; inflorescencias masculinas de $1 \mathrm{a} 2 \mathrm{~m}$ de alto, una a dos veces divididas, con numerosas ramas, el escapo cilíndrico, de 70 a $85 \mathrm{~cm}$ de largo, de 1.2 a $2 \mathrm{~cm}$ de diámetro, el raquis ligeramente flexuoso; brácteas del escapo foliáceas, pajizas, largamente triangulares a triangulares, de 10 a $30 \mathrm{~cm}$ de largo, de 1.8 a $2.5 \mathrm{~cm}$ de ancho en la base, atenuadas y pungentes, las basales imbricadas y mucho más largas que los entrenudos, disminuyendo gradualmente de tamaño hacia el ápice, las vainas ente- 


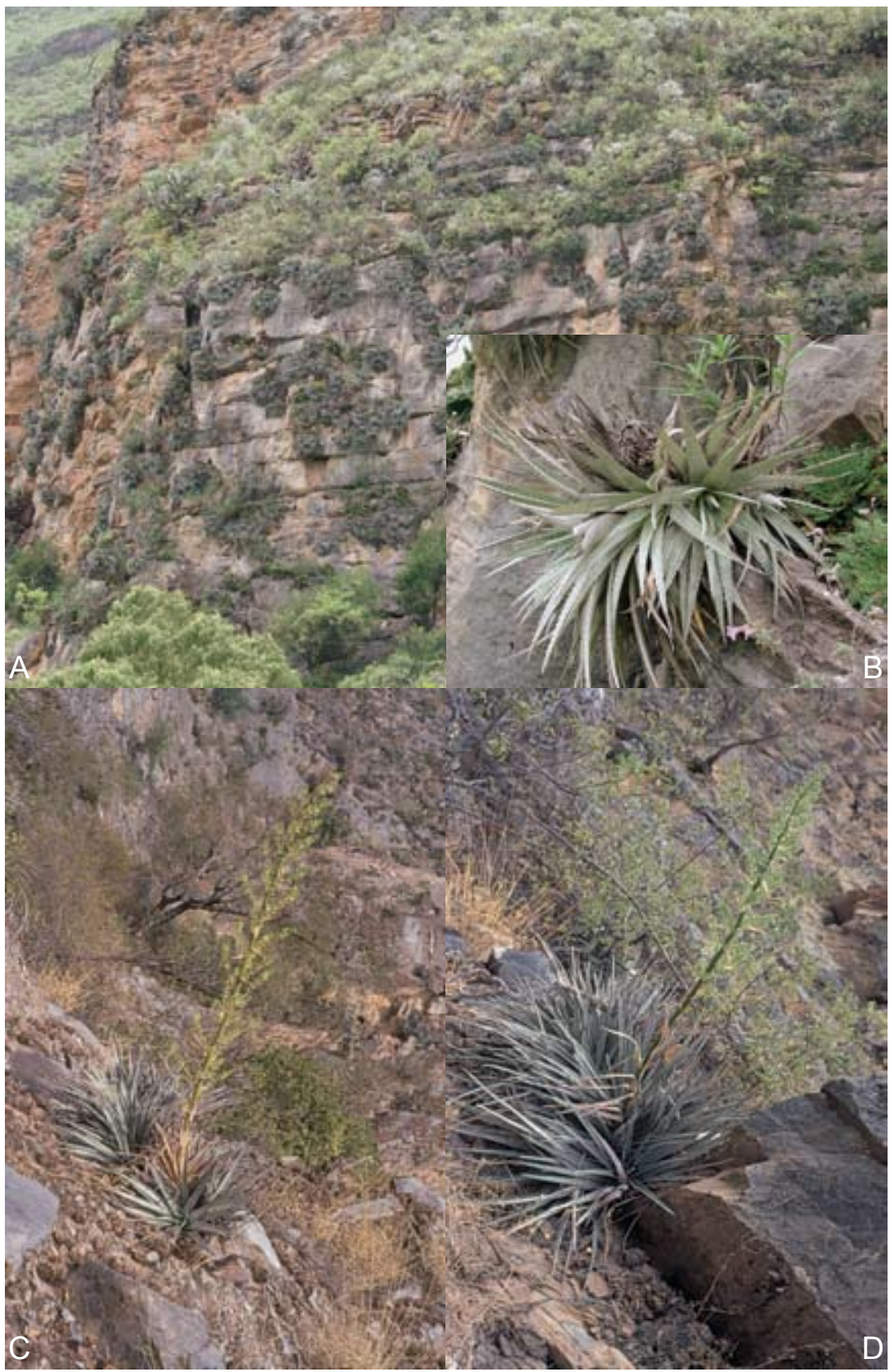

Fig. 2. Hechtia zamudioi. A. población creciendo sobre taludes calizos; B. rosetas; C. planta masculina; D. planta femenina. Fotografías A y B, A. Espejo; C y D, S. Zamudio. 


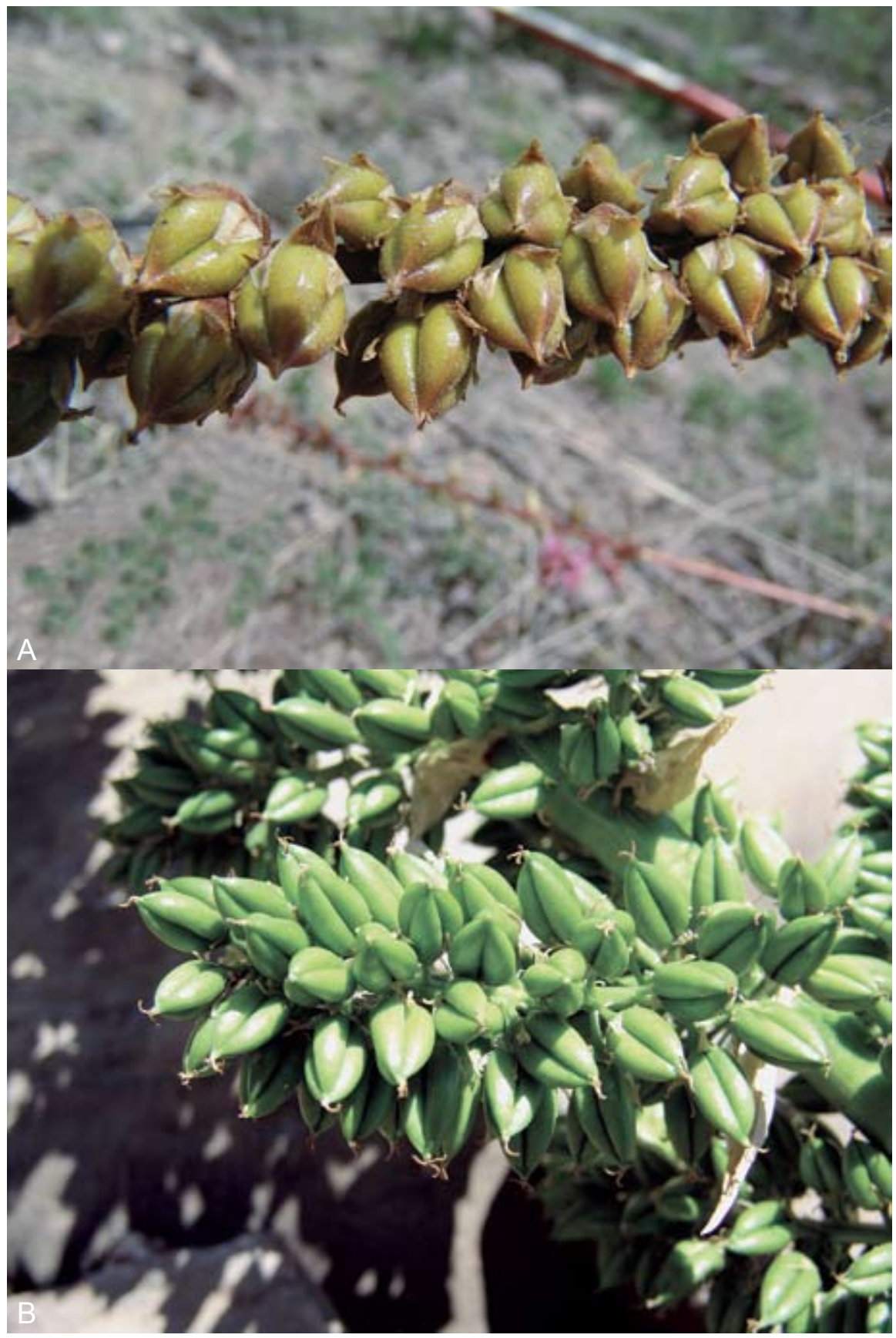

Fig. 3. A. Hechtia pretiosa, frutos; B. Hechtia zamudioi, frutos. 
ras, subcuadradas, de 2 a $2.5 \mathrm{~cm}$ de largo, las láminas espinosas en los márgenes, densamente blanco-lepidotas en ambas superficies, las ramas de primer orden laxas, oblongo-cilíndricas, de 15 a $25 \mathrm{~cm}$ de largo, de 2 a $2.3 \mathrm{~cm}$ de diámetro, con dos ramas de segundo orden de 5 a $9.5 \mathrm{~cm}$ de largo en la base; brácteas primarias pardas claras, papiráceas, largamente triangulares a lanceoladas, de 5.5 a $7 \mathrm{~cm}$ de largo, de 1.5 a $1.7 \mathrm{~cm}$ de ancho, glabras, prominentemente nervadas, acuminadas a largamente acuminadas, hialinas y diminutamente espinosas en los márgenes; brácteas florales filiformes, blancas, inconspicuas, de hasta $3 \mathrm{~mm}$ de largo, enteras, glabras; flores polísticas, divaricadas, sublaxamente dispuestas, numerosas por rama, actinomorfas, largamente pediceladas, los pedicelos filiformes, de 3 a $6 \mathrm{~mm}$ de largo; sépalos libres, verdes, triangulares a ovados u oblongos, de 3.5 a $4.5 \mathrm{~mm}$ de largo, de 2 a 3.5 $\mathrm{mm}$ de ancho, agudos en el ápice, membranáceos, hialinos; pétalos libres, verdes, elípticos, de 6 a $8 \mathrm{~mm}$ de largo, de 3.5 a $4 \mathrm{~mm}$ de ancho, redondeados en el ápice; estambres subiguales, los filamentos lineares a linear-triangulares, de 6 a $7 \mathrm{~mm}$ de largo, las anteras verdes, oblongas, de $3 \mathrm{~mm}$ de largo; ovario vestigial, abortivo; inflorescencias femeninas de 1 a $2 \mathrm{~m}$ de alto, una vez divididas, con numerosas ramas, el escapo cilíndrico, de 70 a $85 \mathrm{~cm}$ de largo, de 1.2 a $2 \mathrm{~cm}$ de diámetro, verde, glabro, el raquis ligeramente flexuoso; brácteas del escapo pajizas, largamente triangulares, de 10 a 30 de largo, de 1.8 a $2.5 \mathrm{~cm}$ de ancho, espinosas en los márgenes, pungentes en el ápice, más largas que los entrenudos, disminuyendo gradualmente de tamaño hacia el ápice de la inflorescencia, las ramas difusas a ascendentes, cilíndricas, una por nudo, de 6 a $10 \mathrm{~cm}$ de largo por 1.7 a $2.3 \mathrm{~cm}$ de diámetro; brácteas primarias lanceoladas a largamente triangulares o largamente ovadas, pardas claras, glabras, papiráceas, de 3.5 a $7 \mathrm{~cm}$ de largo, de 0.9 a $1.5 \mathrm{~cm}$ de ancho, prominentemente nervadas, acuminadas a largamente acuminadas, hialinas y diminutamente espinosas en los márgenes; brácteas florales filiformes, blancas, inconspicuas, de hasta $3 \mathrm{~mm}$ de largo, enteras, glabras; flores polísticas, sublaxamente dispuestas, numerosas por rama, actinomorfas, largamente pediceladas, los pedicelos filiformes, de 5 a $9 \mathrm{~mm}$ de largo; sépalos verdes, triangulares a largamente triangulares, agudos y apiculados, de 3 a $4 \mathrm{~mm}$ de largo, de 1.2 a $1.4 \mathrm{~mm}$ de ancho, membranáceos; pétalos verdes, largamente triangulares a largamente ovados, de 5 a $8 \mathrm{~mm}$ de largo, de 2.5 a $3 \mathrm{~mm}$ de ancho, agudos a redondeados en el ápice; ovario ovoide a elipsoide, de 5 a $7 \mathrm{~mm}$ de largo, de 3 a $4 \mathrm{~mm}$ de diámetro, verde, estigmas tres, filiformes, de 2 a $4 \mathrm{~mm}$ de largo, papilosos en la parte interna; estaminodios 6 , blancos, largamente triangulares a filiformes, de 2.5 a $3 \mathrm{~mm}$ de largo, con anteras vestigiales, inconspicuas. Cápsula verde, parda clara y papirácea cuando seca, ovoide a globoso-ovoide, de 8 a $12 \mathrm{~mm}$ de largo, de 5 a $6 \mathrm{~mm}$ de diámetro; semillas pardas claras, fusiformes, de 5 
a $6 \mathrm{~mm}$ de largo, de ca. $0.5 \mathrm{~mm}$ de diámetro, con una carina longitudinal y con una cauda largamente triangular en el ápice.

Tipo: México, Querétaro, municipio de San Joaquín, cañón del río Estórax, entre El Plátano y Medias Coloradas, laderas de rocas calizas con vegetación de matorral submontano y bosque tropical caducifolio, $875 \mathrm{~m}$, 7-8.III.2000, planta masculina, S. Zamudio y L. Hernández 11285 (holotipo: IEB; isotipo: UAMIZ).

Paratipos: México, Querétaro, municipio de Peñamiller, El Nacimiento, ca. $1.5 \mathrm{~km}$ de La Higuera, rumbo a el balneario El Oasis, ladera caliza con escurrimiento de agua, orientación N, matorral xerófilo con Asclepias linaria, Acacia, Morkilia, Hechtia, Opuntia, $1340 \mathrm{~m}, 21^{\circ} 0.511^{\prime} \mathrm{N}, 9^{\circ} 42.565^{\prime} \mathrm{W}, 12 . \mathrm{VII} .2000$, planta femenina, G. Ocampo, S. Zamudio y A. Reznicek 867 (IEB, UAMIZ); municipio de San Joaquín, cañón del río Estórax, al $\mathrm{N}$ del norte de El Plátano, riscos calizos con vegetación de matorral, 870 m, 10.IV.2007, planta femenina, J. Ceja, A. Espejo, A. R. López-Ferrari, A. Mendoza y S. Zamudio R. 1829 (CICY, IEB, UAMIZ); cañón del río Estórax, entre El Plátano y Medias Coloradas, laderas de rocas calizas con vegetación de matorral submontano y bosque tropical caducifolio, $875 \mathrm{~m}, 7-8$. III.2000, planta femenina, S. Zamudio y L. Hernández 11284 (IEB, UAMIZ).

Otros registros: México, Querétaro, municipio de Peñamiller, ca. $5 \mathrm{~km}$ sobre la desviación al balneario El Oasis, a partir de la carretera Vizarrón - Pinal de Amoles, matorral submontano, 1309 m, 29.VIII.2006, A. Espejo, A. R. López-Ferrari y N. Martínez Correa 6898 (foto UAMIZ); municipio de Pinal de Amoles, 7 km después de El Derramadero, rumbo a Bucareli, taludes calizos con vegetación de matorral, 1600 m, 9.IX.2006, A. Espejo s. n. (foto UAMIZ).

Distribución y hábitat: Hechtia zamudioi se conoce únicamente de los municipios de San Joaquín, Peñamiller y Pinal de Amoles en la cuenca del río Estórax, en el estado de Querétaro (Fig. 4). La especie crece en riscos y paredes de cañones de rocas calizas, cubriendo prácticamente la superficie de los mismos. Resulta extraño que a pesar de lo abundante de las poblaciones y de lo conspicuo de las plantas de la especie, ésta haya pasado hasta ahora desapercibida (Zamudio, 1984).

Etimología: El epíteto específico honra a Sergio Zamudio Ruiz, colega y amigo del Centro Regional del Bajío del Instituto de Ecología A.C., quien realizó las primeras recolecciones de la especie e importante colaborador de la Flora del Bajío y de Regiones Adyacentes. 


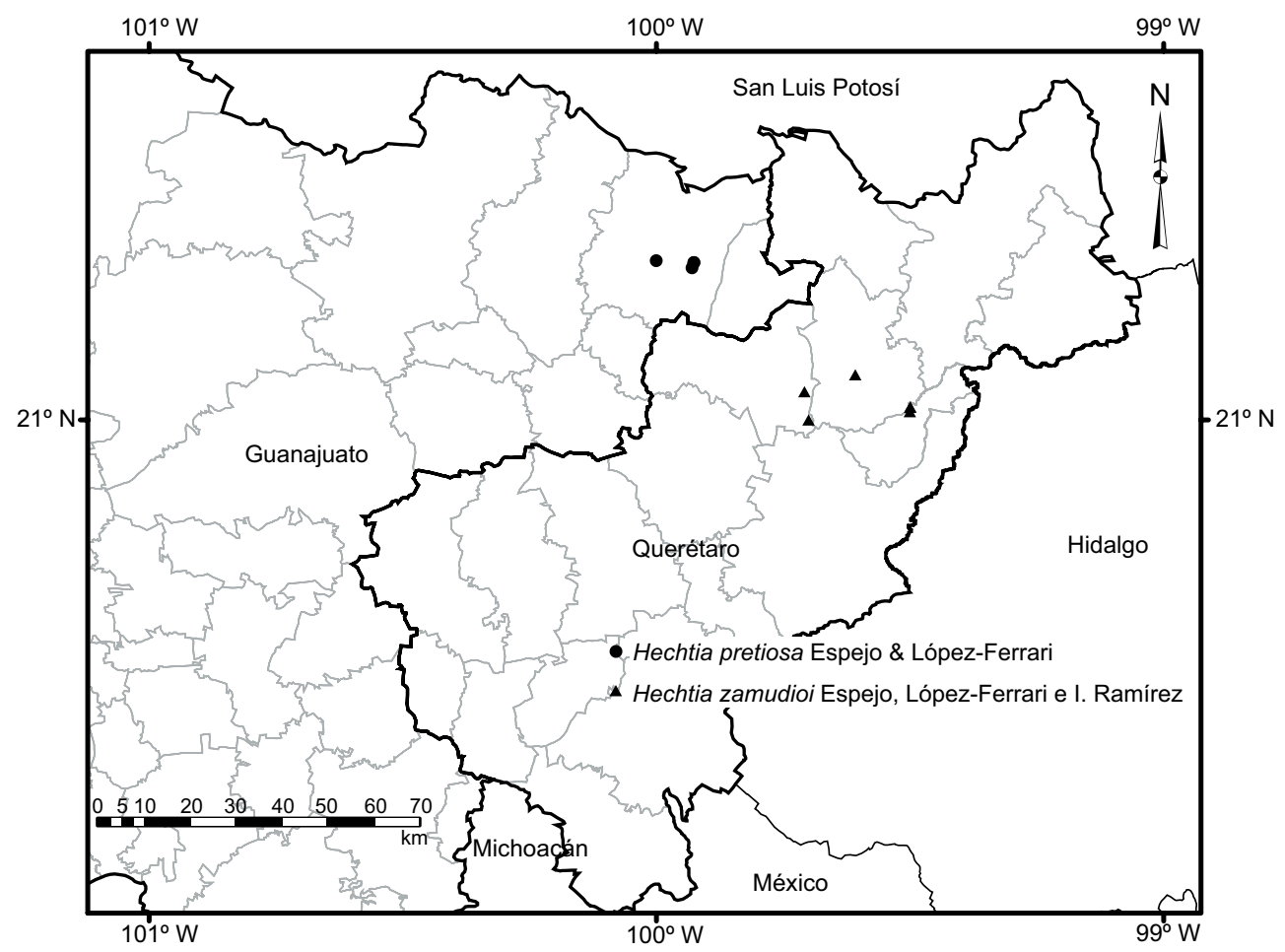

Figura 4. Mapa de distribución de Hechtia pretiosa y H. zamudioi.

Hechtia zamudioi es una especie claramente distinta de cualquier otra del género debido a sus peculiares características: rosetas grandes en forma de estrella con las hojas de color verde azulado y formando extensas colonias, flores largamente pediceladas y sublaxamente dispuestas.

\section{AGRADECIMIENTOS}

Deseamos expresar nuestro sincero agradecimiento a Walter Till, Jerzy Rzedowski y Graciela Calderón por la lectura crítica del trabajo y sus valiosas correcciones al mismo; a Jacqueline Ceja, Aniceto Mendoza y Nancy Martínez Correa por su constante, desinteresada e invaluable ayuda en el trabajo de campo; a Sergio Zamudio, quien nos acompañó en la aventura de recorrer parte del cañón del río Estórax y por facilitarnos material fotográfico de Hechtia zamudioi. Finalmente damos las gracias a los curadores de los herbarios IEB y UAMIZ por brindarnos las facilidades para la consulta del material depositado en sus colecciones. 


\section{LITERATURA CITADA}

Espejo, A., A. R. López-Ferrari, I. Ramírez-Morillo, B. K. Holst, H. E. Luther y W. Till. 2004. Checklist of Mexican Bromeliaceae with notes on species distribution and levels of endemism. Selbyana 25: 33-86.

Espejo-Serna, A., A. R. López-Ferrari, I. Ramírez-Morillo y N. Martínez-Correa. 2007. Dos nuevas especies de Hechtia (Bromeliaceae) de México. Acta Bot. Mex. 78: 97-109.

Graf, A. B. 1980. Exotica, Series 3. Pictorical cyclopedia of exotic plants from tropical and near-tropic regions. 10 ed. Roehrs Co., Nueva Jersey. 1833 pp.

Hernández, L. y S. Zamudio. 2003. Two new remarkable Nolinaceae from Central Mexico. Brittonia 55(3): 226-232.

Luther, H. (comp.) 2006. An alphabetical list of bromeliad binomials. The Bromeliad Society International. 10th ed. Sarasota. $119 \mathrm{pp}$.

Rzedowski, J., G. Calderón de Rzedowski y R. Galván. 1996. Nota sobre la vegetación y la flora del noreste del estado de Guanajuato. Flora del Bajío y de Regiones Adyacentes. Instituto de Ecología, A.C. Fascículo complementario XIV. Pátzcuaro, Mich. 22 pp.

Zamudio, S. 1984. La vegetación de la cuenca del río Estórax, en el estado de Querétaro y sus relaciones fitogeográficas. Tesis de licenciatura. Facultad de Ciencias, Universidad Nacional Autónoma de México. México, D.F. 275 pp. 